\title{
LA ACUMULACIÓN DE AUTOS EN EL PROCEDIMIENTO CONCESIONAL MINERO
}

\author{
Alberto Tala Japaz \\ Profesor de Derecho de Minería, de Aguas y Ambiental en la \\ Escuela de Derecho Universidad Católica del Norte \\ Antofagasta
}

\section{1.- ASPECTOS GENERALES}

El modelo concesional minero vigente de raigambre constitucional, persigue definir jurídicamente los procedimientos y derechos que creen el marco de seguridad y certeza jurídicas suficiente para un adecuado desarrollo de la industria minera, dentro del contexto de los principios y valores asociados al desenvolvimiento de la economía plasmados en la Constitución de 1980, pudiéndose hablar hoy de un orden público económico minero. Este último estaría configurado por las especiales regulaciones de la actividad económica minera, adecuadamente conjugadas con el estatuto general de la economía en Chile, pese a ser el Derecho Minero particularmente diferencial en algunos aspectos fundamentales.

Así las cosas, compartimos plenamente los criterios establecidos por los autores, según los cuales hoy día buena parte de los conflictos jurídicos económicos han devenido temas constitucionales. ${ }^{113}$

Ahora bien: la estructura y definición constitucionales del núcleo del régimen de aprovechamiento minero chileno, ponen de manifiesto cómo dicha constitucionalización de los temas es efectiva y concreta. ${ }^{11}$

Es sabido que la Ley Orgánica Constitucional sobre Concesiones Mineras, junto al Código de Minería del año 1983, han pretendido cuajar dichos principios y valores constitucionales, en el detalle y pormenorización del estatuto jurídico de la minería en Chile.

No obstante, ya se han advertido variados aspectos de la legislación en la que ésta no resultaría del todo conforme a la Constitución. ${ }^{11}$

\footnotetext{
${ }^{113}$ En tal sentido, desde el ámbito del Derecho Privado, lo sostiene claramente Rodríguez Grez, Pablo. Inexistencia y Nulidad en el Código Civil Chileno. Editorial Jurídica de Chile. 1995. Pags. 304 y sgtes. Por cierto, en el mismo sentido, Cea Egaña, José Luis. Tratado de la Constitución de 1980. Editonal Jurídica de Chile. 1988. Pags. 181 y sgtes.

114 Carlos Ruiz Bourgeois en diversas ocasiones ha enfatizado la peculiaridad del ordenamiento constitucional chileno, que, como pocos, se refiere a la minería. Ello estaría basado en que Chile culturalmente es un país minero, Véase, por todos, Ruíz Bourgeois, Carlos. "Fundamentos Constitucionales del Derecho de Minería". En: Revista de Derecho de Minas y Aguas. Vol. 1. 1990. Pags. 75 y sgtes.

${ }^{115}$ Posiblemente por esa misma constitucionalización de los temas de propiedad, en el último tiempo se han planteado con mayor o menor plausibilidad, varias irnpugnaciones constitucionales al Código de Minería. Así es como, en el tema de superposiciones de concesiones, se armó un amplio debate, rechazado en definitiva en el Parlamento y en la Corte Suprema. También se ha
} 
Con todo, resulta ser también manifiesta la aplicación directa de la Constitución Política de la República en sede minera, integrando automáticamente la legalidad de aplicación inmediata, lo que valida aún más la constitucionalización de los conflictos jurídicos mineros, y por consiguiente la resolución de los mismos ya desde la propia Ley Fundamental.

En efecto, así como resulta evidentemente anticonstitucional el otorgamiento de una concesión minera por el Director del Servicio de Registro Civil, o por un país extraño en nuestro territorio, es manifiesto que dichas antijuridicidades no emanan de un prurito interpretativo legal, sino de las bases mismas del sistema jurídico de aprovechamiento minero, como es el principio de legalidad y el principio de supremacía constitucional, aplicados directamente al Derecho Minero, según los cuales todo acto de un órgano del Estado debe realizarse previa investidura regular de sus integrantes, dentro de su competencia y en la forma prescrita por la ley; como asimismo que los preceptos de la Constitución obligan no sólo a los órganos del Estado sino a toda persona, institución o grupo (artículos 6 y 7 de la Constitución Política de la República).

Por consiguiente, se aprecia en forma obvia cómo las situaciones señaladas son anticonstitucionales desde un punto de vista orgánico, por tratarse de órganos incompetentes funcional y territorialmente,

Pero también la aplicación real del procedimiento concesional legislado en el Código de Minería, ha suscitado cuestiones de constitucionalidad vinculadas al procedimiento, que es necesario esclarecer y resolver con el fin de mantener los principios jurídicos que hacen posible el desarrollo del sistema económico de aprovechamiento minero.

Un punto como el señalado, es el derivado de la acumulación de autos en el procedimiento concesional minero.

Efectivamente, ha sido necesario construir un procedimiento legislado detalladamente, con el fin de asignar adecuadamente el recurso minero para su aprovechamiento, sobre la base de otorgar la concesión minera de explotación o pertenencia al descubridor del yacimiento sobre el cual se desea constituir dicha misma concesión.

Es imposible que dicha concesión minera fuere constituida y otorgada en dominio en un sólo acto instantáneo y eficaz para tal objeto.

Ello, por cuanto dentro del procedimiento concesional -que por lo mismo no puede menos que desarrollarse en un lapso de tiempo considerable y de acuerdo a las fases o etapas previstas en la ley- deben cumplirse los siguientes objetivos. ${ }^{116}$

a) Definir quién es el titular de la concesión minera solicitada.

criticado la vinculación del Juez a acceder a la solicitud cuando haya informe favorable del Servicio, en el caso del artículo 53 del Código de Mi ería.

También se ha suscitado cuestión la llamada aplicación retroactiva del artículo 17 del Código de Minería.

116 Practicamente todos los autores de libros de texto en Derecho de Minería, remarcan la necesidad de que el sistema jurídico minero persiga dichos objetivos. Así, Lira Ovalle, Samuel. Curso de Derecho de Minería. Editorial Jurídica de Chile. 1992. Hay reedición. Ossa Bulnes, Juan Luis, Derecho de Minería. 1992 . Gomez Nuñez, Sergio. Manual de Derecho de Minería. Editorial Jurídica de Chile. 1991. 
b) Definir si tal titular tiene efectivamente derechos mineros preferentes por el descubrimiento que reconocer.

c) Definir espacialmente la parcela de aprovechamiento que se solicita. concesiones.

d) Cumplir las cargas económicas previstas en la ley para el otorgamiento de

e) Permitir que todo tercero que se sienta perjudicado por la concesión minera solicitada, pueda legalmente oponerse a su otorgamiento en el marco de un justo y racional procedimiento.

f) Evitar en lo posible el otorgamiento de concesiones mineras contradictorias, como sería otorgar la misma concesión espacialmente a dos o más personas diferentes con derechos exclusivos cada una de ellas.

g) Incorporar la concesión minera al sistema de catastro y al sistema registral inmobiliario, para la adecuada circulación de la propiedad.

Pues bien: en ese escenario, como se dijo, entonces, el legislador echó mano de un conjunto de instrumentos jurídicos para diseñar un procedimiento que efectivamente cumpla con dicho objetivo.

Así, existen en general una fase petitoria, otra fase de concreción y finalmente una última fase de otorgamiento de la concesión propiamente tal. ${ }^{117}$

Lo anterior, bajo la forma de un procedimiento judicial voluntario o no contencioso, sin intervención decisoria alguna de otra autoridad o persona distinta al Juez competente para conocer de dicho mismo procedimiento, y sin que pueda haber intervención de terceros por la vía de la oposición o de la acumulación de autos fuera de los casos estrictamente permitidos en forma expresa por la ley.

Es decir, para cumplir eficazmente los objetivos señalados, de raigambre constitucional -y fundamentalmente vinculados a la pronta constitución para la pronta explotación de la pertenencia minera- el procedimiento concesional judicial es diferencial, sobre todo en cuanto a las posibilidades de intervención de terceros y de acumulación de autos.

Efectivamente, los terceros sólo pueden intervenir judicialmente en relación a un procedimiento concesional minero, de las siguientes formas:

a) Mediante un juicio separado de mejor derecho, sin que se paralice el procedimiento concesional.

b) Mediante un juicio separado de caducidad o cualquiera otra impugnaciones que deseen hacerse, sin paralizar el juicio principal, notificada la demanda antes de la dictación de la sentencia constitutiva, y siempre que no se trate de un error meramente procesal que deba resolverse y sanearme in limini litis. ${ }^{118}$

${ }^{117}$ Como se sabe, la voz concesión tiene una polisignificación que a veces corfunde su exacto sentido. Posiblemente, el sentido mas propio sea como verbo transitivo de la acción de conceder y el efecto de dicho mismo acto. En tal sentido, se otorga la concesión propiamente tal.

${ }^{118}$ Por una disputa muy amplia, que practicamente puso a prueba toda la vocación de certeza jurídica de la nueva legislación minera chilena, sentó dicho principio la Excelentísima Corte Suprema en fallo de 4 de Mayo de 1990, que se lee en anexo $N^{2} 1$ 
c) Mediante un escrito de téngase presente conforme al artículo 86 del Código de Minería, que tampoco paraliza el procedimiento constitucional, añadiendo únicamente el trámite de la consulta de la sentencia constitutiva en caso de que se niegue lugar a la caducidad, procesada sin forma de juicio.

d) La solicitud de caducidad conforme al artículo 70 del Código de Minería. ${ }^{119}$

e) La demanda de oposición a la constitución de concesión minera de explotación, conforme al artículo 84 del Código Minero.

f) La demanda de nulidad de concesión minera conforme al artículo 95 y siguientes del Código Minero.

Además, se contempla la especialísima norma de otorgar efecto negativo de cosa juzgada por la vía de la excepción, a la sentencia constitutiva minera ejecutoriada.

En ese orden de ideas, entonces, es claro el principio de orden público de mínima intervención de terceros en el procedimiento concesional minero, reducida a los únicos casos señalados de intervención -no todos en el mismo procedimiento concesional- y a limitadísimos casos de acumulación de autos.

En este aspecto, bien vale la pena preguntarse si se trata de una genuina acumulación de autos y en qué casos puede ella verificarse.

Pues bien: una adecuada respuesta a dichas cuestiones, supone hacerse cargo en primer lugar de la segunda de ellas.

\section{2.- ¿HAY GENUINA ACUMULACION DE AUTOS EN EL PROCEDIMIENTO CONCESIONAL MINERO?}

En efecto, la acumulación de autos, entonces, cualesquiera sea su genuina naturaleza jurídica, está en general proscrita en los procedimientos voluntarios y contenciosos mineros, y sólo permitida en los siguientes casos:

a) En la oposición obligatoria a la solicitud de mensura en base a una manifestación minera en trámite, en donde ya se ha solicitado mensura, siendo el oponente el manifestante anterior o que se tenga por anterior, conforme al artículo 63, inciso primero, del Código de Minería, conforme al cual: "en el mismo escrito de oposición, pedirá que se ordene la acumulación de su expediente de manifestación al del demandado".

b) En la oposición voluntaria a la solicitud de mensura de un manifestante de fecha posterior que solicita mensura después que el primero, conforme al artículo 66, inciso primero, segunda parte, del Código de Minería, según el cual "en este caso, el opositor deberá, además, cumplir con lo dispuesto en el artículo 63, esto es, solicitar la acumulación de autos.

En ninguno de todos los otros casos de oposición a la solicitud de mensura, procede la acumulación de autos en el sentido que legisla el Código de Minería, sea

\footnotetext{
19 del año 1990, de la Revista Gaceta Jurídica.

${ }^{119}$ Con algún detalle en esta materia, puede consultarse nuestra obra caducidad de derechos mineros. El articulo 70 en Código de Minería. Editorial Jurídica Conosur 1994.
} 
porque sencillamente en el expediente en el que se plantea la oposición no va a haber ningún tipo de agregación de los antecedentes otros que sirven de base a la oposición, o bien no hay acumulación de autos porque los resultados prácticos de esta última están ya cumplidos a cabalidad por el efecto de solicitar mensura anticipada, acompañando entonces los documentos fundantes de la misma, en el expediente en el cual se hace la oposición, siendo entonces el conjunto de documentos aparejados a la solicitud de mensura así planteada una virtual acumulación, porque esos mismos documentos serían todos e idénticos a los que se acumularían con un expediente respectivo.

En efecto, entonces, pues, sencillamente sólo hay acumulación de autos propiamente tal -en el sentido de la legislación minera- en el caso de oposición obligatoria del inciso primer del artículo 63 y en el caso de oposición voluntaria del inciso primero del artículo 66.

En todos los otros casos de oposición a la solicitud de mensura, que se desprenden de las dos causales taxativamente indicadas en el artículo 61 del Código de Minería, no hay acumulación de autos por las razones indicadas supra.

Así las cosas, nunca habrá acumulación de autos cuando se entable una demanda de oposición a la solicitud de mensura en base a los derechos emanados de un pedimento minero o de una concesión minera para explorar original o prorrogada. Aquí, sencillamente, el procedimiento concesional de exploración minera correrá por cuerda separada, si está en trámite, o sencillamente permanecerá en su Tribunal de origen archivado si está afinado, y sólo se agregarán al expediente en el cual se hace oposición, las piezas pertinentes exigidas por el inciso segundo del número primero del artículo 61 del Código Minero.

Ello, tiene una justificación técnico-procesal, consistente en que no sería razonable acumular expedientes en donde verdaderamente no hay ninguna identidad ni de cosa pedida, ni de causa de pedir, sin ser realmente importante la identidad legal de personas. Porque, en efecto, en el procedimiento constitutivo de una concesión para explorar, en trámite o afinado, sencillamente hay eso, el otorgamiento de un derecho real exclusivo para explorar un yacimiento minero dentro de un ámbito espacial determinado, sin que en realidad se esté pidiendo en ese momento la mensura, o sea, sin que el juicio verse sobre la declaración del derecho preferente para mensurar, allí y en ese momento, una pertenencia determinada. Dicho de otro modo, a diferencia de las oposiciones a la solicitud de mensura establecidas en el numeral 2 de dicho mismo artículo 61, que sí versan sobre la definición alternativa del derecho preferente a mensurar entre las partes y litigios, como dice el artículo 69, inciso primero, del Código de Minería, "la sentencia que acoja una demanda de oposición basada en la causal primera del artículo 61, declarará que el demandado no podrá mensurar dentro del perímetro del pedimento, del de la concesión de exploración o del de la parte en que ésta no haya sido renunciada, en su caso". En cambio, conforme al inciso segundo de dicho mismo artículo 69, "la sentencia que acoja una demanda de oposición fundada en la causal segunda del artículo 61 , reconocerá el derecho preferente del primer manifestante a mensurar su pertenencia o pertenencias, en la forma indicada en la respectiva solicitud; $y$, en cuanto no afecte a ese derecho preferente, reconocerá también del derecho de la parte vencida a mensurar con arreglo a su propia solicitud, pero respetando íntegramente el derecho preferente de la parte vencedora".

Es decir, en estos casos no hay acumulación de autos porque no hay identidades de cosa pedida o de causa de pedir, que así lo pudieren justificar. Dicho de otro modo, 
acumular los autos en estas especies sería una deseconomía procesal, puesto que si bien puede tratarse de algún género de derechos mineros atingentes a una misma área, la diferente naturaleza y estado de tramitación de los mismos hace antijurídica su posible acumulación, que redundaría en una violación al mismo principio rector del artículo 34 , inciso segundo, del Código Minero, puesto que se haría menos pronta la constitución de la concesión minera.

Ahora bien: el caso en que un pedimento o concesión de exploración antelados den preferencia a una manifestación minera en trámite ulterior, y este conjunto entre en conflicto con una solicitud de mensura emanada de derechos posteriores, no se trata de un conflicto del número primero sino del número segundo del artículo 61, porque en realidad ya hay manifestaciones mineras con solicitudes de mensura en conflicto, lo que escapa al caso del número primero en todas sus variantes, no obstante que, en alguna medida, son situaciones cercanas, puesto que existe en el origen del conflicto un derecho minero de exploración. ${ }^{120}$

Por otro lado, así como nunca hay acumulación de autos cuando se demanda en base a un derecho de exploración minera, los únicos casos en que tal acumulación es permisible en relación a un procedimiento concesional minero regido por la regla del artículo 34 del Código del rubro, se dan, como se dijo, cuando se demanda en base a derechos emanados de una manifestación minera antélàdã.

Pero aún así, no en todos los casos en que se demanda en base a una manifestación minera antelada, habrá acumulación de autos,

En efecto, como se sabe, hay que distinguir las oposiciones a la solicitud de mensura facultativas y obligatorias, en base a manifestación minera, puesto que en base a derechos mineros de exploración, se trata siempre de oposiciones obligatorias. Y, además, pensamos, debe distinguirse y conjugarse los casos anteriores con los casos en que es obligatorio solicitar acumulación de autos, o los casos en que ello no es obligatorio.

Pues bien: son oposiciones obligatorias a la solicitud de mensura en base a un derecho preferente emanado de una manifestación minera, todos aquellos en que se trate de una manifestación anterior o que se tenga por anterior en que se hace oposición a una manifestación posterior o que se tenga por posterior, que solicita mensura antes que la manifestación antelada o que se tenga por antelada.

Por la inversa, son oposiciones a la solicitud de mensura voluntarias todas aquellas en que el manifestante antelado o que se tenga por antelado hace oposición a una manifestación posterior o que se tenga por posterior, y que solicita mensura esta última después que el manifestante antelado o que se tenga por antelado.

Ahora bien: en los casos de oposiciones a la solicitud de mensura obligatorias señalados, a su vez hay que distinguir si, antes que comience a correr el plazo de 30 días contados desde la publicación de la solicitud de mensura, el manifestante antelado o que se tenga por antelado ha solicitado o no, respectivamente, su mensura.

En el caso que el manifestante antelado o que se tenga por antelado que vaya a demandar al manifestante postelado que no obstante ha solicitado su mensura antes que la del preferente sin que el preferente a su vez haya solicitado su mensura antes de que

${ }^{120}$ En este caso, realmente, no se produciria un juicio de oposición a la solicitud de mensura propiamente tal 
comience a correr el plazo para entablar la oposición, en ese caso, no hay acumulación de autos, y el oponente deberá solicitar su mensura preferente en un otrosí de su demanda de oposición, adjuntando a dicha oposición todos los documentos exigibles para dicho trámite conforme al artículo 59 del Código Minero, trámite que se avanzará hasta la publicación de esa respectiva solicitud de mensura del oponente, deteniéndose allí el trámite no contencioso, haya o no oposición a la solicitud de mensura del oponente, hasta esperar a que se resuelva el juicio de oposición a la solicitud de mensura, definiendo el derecho preferente para mensurar en los términos del los artículos 69 y 70 , inciso segundo, del Código Minero. ${ }^{121}$

Sin embargo, pese a que no existe una acumulación así denominada en esta especie, se produce sí una acumulación virtual, a consecuencia de todos los documentos que se aparejan conforme al artículo 59 junto a la solicitud de mesura que se hace en un otrosí de la demanda, puesto que la sumatoria de tales documentos aparejados sería un expediente constitutivo minero completo hasta la fase de solicitud de mensura de pertenencia minera.

Ahora bien: en el mismo caso, esto es, tratándose de un manifestante antelado o que se tenga por antelado, que vaya a hacer oposición a un manifestante posterior o que se tenga por posterior, que ha solicitado mensura antes que el preferente, pero, no obstante, habiendo por su parte el manifestante preferente alcanzado a solicitar mensura antes que corra el plazo para entablar su oposición, en ese caso, hay acumulación de autos, puesto que se agrega el conjunto del expediente del manifestante preferente con su solicitud de mensura y documentos aparejados conforme al artículo 59 del Código de Minería, al expediente al cual se hace oposición.

Por otra parte, en el caso de la oposición voluntaria la acumulación de autos es obligatoria, es decir, sólo es potestativo para el manifestante preferente que ya solicitó mensura antes que el manifestante postelado que también solicita mensura con posterioridad, y al cual se desea hacerle oposición, es potestativo solamente, decimos, decidir si se entabla o no la oposición, pero si se decide hacerlo, es obligatorio solicitar la acumulación de autos en un otrosí.

Vale la pena destacar que si se trata de oposiciones obligatorias, esto es, que deben necesariamente entablarse legalmente dentro de plazo fatal bajo sanción de caducidad, dicha caducidad también se configurará si, no obstante haberse entablado la demanda, no hay acumulación de autos obligatoria solicitada en su caso junto a ella.

Sin embargo, según establecimos supra, vistos los únicos casos en que procede la acumulación de autos en el procedimiento concesional minero, de acuerdo a la regla general del artículo 34 del Código de Minería, debe definirse si en dogmática jurídica se trata de una verdadera acumulación de autos y qué consecuencias prácticas acarrea ello.

Pues bien: la acumulación de autos es un incidente de previo y especial pronunciamiento legislado en el Código de Procedimiento Civil, en sus artículos 92 y siguientes y que consiste, esencialmente, en la reunión de dos procesos contenciosos o

${ }^{1,1}$ Cabe enfatizar lo que a veces suele confundirse en la práctica judicial. Cuando se acumulen los autos en cualquier sentido por efecto de una dernanda de oposición a la solicitud de mensura, jamás dichos antecedentes se desacumularán. $Y$ si existe derecho para ello, la mensura será en el nuevo expediente, 
juicios diversos, cuando tienen alguna relación especialmente definida en la ley entre ellos, para que sean tramitados conjuntamente y resueltos en una misma sentencia.

Se ha dicho, históricamente, que la causal fundamental de la acumulación de autos en general es mantener la continencia o unidad de la causa, frase tradicional pero no con un sentido completamente claro, y que aproximadamente podríamos traducir como la evitación de sentencias contradictorias. ${ }^{122}$

Ese especial vínculo entre los procesos, hoy los procesalistas lo denominan, parafraseando el instituto de Derecho Internacional Privado, vínculo de conexión o de conexidad.

Asimismo, puede decirse que existen múltiples instituciones procesales que implican en términos reales una genuina acumulación de autos, como son la acumulación de acciones, la pluralidad de partes y la demanda reconvencional.

Por otro lado, sin embargo, existen las llamadas acumulaciones en el procedimiento penal y en los procedimientos universales, que más bien pueden ser denominados como vis atractiva de ciertos procesos.

Así es como todos los procesos incoados por distintos delitos cometidos por una misma persona, como asimismo todos los créditos que se tengan en contra de una misma persona declarada en quiebra, deben ser procesados en un mismo juicio, individual en el caso penal, y universal en el caso de la quiebra.

\section{¿En cuál de los dos extremos estaría la acumulación de autos del Derecho Minero?}

Para contestar esa pregunta, de la cual se derivan importantes consecuencias, particularmente en lo relativo a la aplicación de la caducidad legislada en el artículo 70 del Código de Minería, hay que hacer algunas precisiones.

Desde luego, bien podría decirse que todo el estatuto de la acumulación minera repugna a la acumulación legislada en el Código de Procedimiento Civil, como norma general y referente obligatorio en esta materia.

En primer lugar, las normas de la acumulación de autos exigen que los procesos estén sometidos a un mismo procedimiento, cosa que no ocurre en la acumulación minera, porque el proceso contencioso judicial es un procedimiento sumario, y el procedimiento constitutivo minero que se acumula y se suspende en su tramitación, está regido por las normas especiales de procedimiento constitutivo del Código de Minería.

En segundo lugar, y obviamente, repugna la acumulación de autos minera a las normas generales sobre acumulación de autos que exigen que se trate de procedimientos contenciosos, de juicios -aunque no esté trabada la litis- pero en ningún caso el Derecho Procesal Civil ha permitido la acumulación de un expediente voluntario a un juicio.

En tercer lugar, porque en sede general una vez decretada la acumulación de autos, el procedimiento más avanzado debe detenerse hasta que alcance su estado el procedimiento más antiguo, de modo que ulteriormente sigan una tramitación paralela, lo que obviamente no ocurre en la acumulación minera, en donde el expediente constitutivo minero acumulado suspende su tramitación hasta que se afine el juicio al cual se acumuló

1* Aparentemente el único sentido real de la expresion "mantener la continencia o unidad de la causa" es ese. Véase, Armenta Deu, Teresa. La acumulación de autos. Editonal Montecorvo S.A. Año 1983. Pags. 40 y sgtes. 
dicho expediente, lo que ciertamente rompe con la norma establecida en el artículo 97 del Código de Procedimiento Civil que es la completamente contraria.

Además, la tramitación de esta acumulación de autos minera, es diversa, porque en sede general su planteamiento suscita un incidente de previo y especial pronunciamiento, que debe ser resuelto con audiencia real o ficta de la otra parte, lo que no ocurre en esta especie, en donde el Juez debe acceder desde luego a la acumulación. quedando pendiente únicamente el cumplimiento material de dicha resolución.

En resumen, y como claramente se ve, la acumulación de autos minera nada tiene que ver con la acumulación de autos general del Código de Procedimiento Civil.

Faltaría determinar, entonces, si en vez de acumulación de autos propiamente tal -que como se dijo, no es- se trata entonces de un efecto atractivo de un procedimiento universal, en la línea de la acumulación de autos legislada en la ley de quiebras. Pero tampoco hay tal.

Ello, por cuanto es absolutamente evidente que un juicio de oposición a la solicitud de mensura no es un juicio universal, sino únicamente un procedimiento contencioso sumario singular, en el que pueden aparecer otras partes demandantes eventualmente.

\section{3.- NATURALEZA JURIDICA DE LA ACUMULACION DE AUTOS $Y$ EFECTOS DE TODO ELLO EN EL PROCEDIMIENTO CONCESIONAL MINERO}

Además, en la ley de quiebras los procedimientos se acumulan únicamente en el sentido de que deviene una transferencia de competencia desde el Tribunal ante el cual estaba radicado el conocimiento del juicio, hacia el Tribunal que conoce del expediente de la quiebra, para que intervenga también el síndico en representación del demandado fallido o demandante.

Consecuentemente, el efecto atractivo de la quiebra como procedimiento universal mal Ilamado acumulación de autos, es sólo una excepción a la regla orgánica de competencia de la radicación, establecida en el artículo 109 del Código Orgánico de Tribunales, según el cual radicado con arreglo a la ley el conocimiento de un negocio ante Tribunal competente, no se alterará esta competencia por causa sobreviniente.

Por lo tanto, tampoco la acumulación minera es una especie de efecto atractivo universal del juicio de oposición a la solicitud de mensura, que es singular.

Y obviamente la conclusión del Derecho Minero en esta materia -como en tantas otras- es que la acumulación de autos en minería es sui géneris.

Dicha acumulación de autos rompe con todos los modelos y referentes del procedimiento civil y comercial.

Es especial también en su estructura y efectos, como asimismo en su tramitación, siendo dable entonces perfilar dogmáticamente este especial estatuto de la acumulación de autos en materia minera.

Procede la acumulación de autos en Derecho de Minería en casos diversos a los señalados en el Derecho Común. En efecto, para acumular otro expediente al 
procedimiento no contencioso constitutivo de una concesión minera, que ha devenido contencioso por efecto de la presentación de una demanda de oposición a la solicitud de mensura, no se exige la concurrencia de ninguna de las hipótesis legisladas en el artículo 92 del Código de Procedimiento Civil, sino los casos especialmente indicados supra.

En la tramitación de la acumulación de autos, no se forma ningún incidente sino que el Tribunal debe decretarla desde luego, existiendo únicamente la posibilidad de que se planteen cuestiones derivadas del cumplimiento material de dicha resolución judicial de acumulación, consistentes en que, no obstante estar decretada la acumulación de autos y por ello transferida la compentencia del Tribunal de origen ante el cual está radicado el conocimiento del expediente constitutivo, dicha resolución no se cumpla materialmente y continúe dicho Tribunal conociendo del otorgamiento de la concesión, lo cual haga efectivamente dictando la sentencia concesional. Estos casos, como veremos infra, con amplia aceptación en la doctrina y jurisprudencia, han sido resueltos en base a nuestra tesis de la nulidad de Derecho Público en materia minera. ${ }^{123}$

Consecuentemente, el efecto que produce la acumulación de autos minera es trasladar de manera irrevocable y definitiva la competencia del Tribunal para conocer del procedimiento concesional, que pasa a ser aquél en el cual se cumple la acumulación. Pero, al mismo tiempo, el efecto de la acumulación de autos es suspender la tramitación de los procedimientos constitutivos no contenciosos acumulados, hasta tanto se resuelva el juicio de oposición.

Ahora bien: la acumulación de autos minera en ese sentido, no es más que la consecuencia de la acumulación de acciones que se ventila en el juicio de oposición a la solicitud de mensura. En efecto, el planteamiento de una sola demanda de oposición, suscita una discusión judicial anterior al otorgamiento de las concesiones mismas, cual es definir quién tiene derecho preferente para mensurar en terreno su pretensión de acuerdo al derecho del descubridor consignado en el artículo 5, inciso tercero, de la Ley Orgánica Constitucional sobre Concesiones Mineras.

Lo que ocurre es que el oponente es demandante, y el primer solicitante de mensura demandado. Allí, virtualmente, hay acumulados en un sentido figurado dos pretensiones por la vía de la acción de oposición y de la excepción que corresponda. Sin embargo, junto a esta situación, normalmente ocurrirá que a la primitiva solicitud de mensura no se le hará una oposición sino múltiples, cada una de las cuales implicará la acumulación de autos que se solicite, o, a su vez, una solicitud de mensura en el otrosí a la cual por su parte se le haga también oposición.

¿Cómo resolver ese cúmulo de demandas, de acciones y eventuales excepciones? no fácil.

Ese tema se plantea cotidianamente y suscita cuestiones procesales de resolución

Desde luego, un principio rector en esta materia es el que se deriva del propio artículo 68 del Código de Minería, según el cual: "todas las oposiciones a que se refiere el artículo 61 se tramitarán con arreglo al procedimiento señalado en el artículo 233. En el juicio se tendrá por demandante al opositor, y solo será admisible como única defensa del

${ }^{123}$ Un amplio fundamento desde el ámbito constitucional en esta materia, con un pormenorizado desarrollo, se encuentra en Soto Kloss, Eduardo. Derecho Administrativo. Bases Fundamentales. El Principio de Juridicidad. Editorial Jurídica de Chile. Tomo 2. Año 1996. Pags. 163 y sgtes. 
demandado la de que su solicitud de mensura no abarca los terrenos comprendidos en el pedimento, en la concesión de exploración o en la solicitud de mensura en que se funda la acción". Agregando el inciso segundo que: "cualquiera otra defensa y toda excepción perentoria que puedan corresponder al demandado sólo podrán hacerse valer por éste, como acciones, en juicio separado".

Por cierto, es casi la cuadratura del círculo en el procedimiento minero. ¿Cómo hacer sustanciar la secuela del procedimiento con tantos demandantes y demandados?

Es desde luego acumulación de acciones y participación de diversos sujetos. ${ }^{124}$

Sin embargo, sus intereses pueden ser contrarios entre sí, por lo que no parece correcto jurídicamente aplicarles a todos los demandantes ulteriores al primero las normas de las tercerías, y hacerles nombrar un procurador común. Por lo demás, las situaciones de los diversos demandantes debe ser esclarecida precisamente en ese juicio, para resolver lo pertinente.

A nuestro modo de ver, se trataría de una acumulación de acciones, en el procedimiento sumario, que en todo caso debe dar lugar a un solo juicio, y de acuerdo a un solo procedimiento sumario aplicado. Es decir, debe existir un solo comparendo de contestación, un solo término probatorio, una sola citación para oír sentencia y un solo fallo.

En efecto, el texto de la ley habla de "todas las oposiciones", "con arreglo al procedimiento señalado", "en el juicio", etcétera. Y, por su parte, el artículo 69 habla de "la sentencia" en varias ocasiones.

Las consecuencias de todo lo anterior llegan al artículo 70 del Código de Minería, que establece sanciones de caducidad, y que haría perder todos los derechos mineros procesados en un juicio nulo en el procedimiento, que implique que las gestiones hechas en él fueron nulas y por lo tanto inútiles por más de tres meses, configurándose la infracción sancionada con caducidad.

Posiblemente la fase procesal más compleja para aplicar un sólo procedimiento sea el del comparendo de contestación. Es difícil notificar personalmente a todos los demandados para que lleguen a la misma audiencia de contestación. Es difícil definir el día de esa misma audiencia, si no se sabe si fueron o no notificados los otros demandados.

Con todo, dicha dificultad es más aparente que real: se puede citar a comparendo para el quinto día después de la última notificación de todas las demandas que se planteen en el proceso; puede eventualmente ordenarse la notificación por avisos en la prensa si ya se sabe que habrán múltiples demandantes, etcétera.

Y esa solución además de apegada a la ley nos parece justa en lo material, en la medida que franquea a todos la posibilidad de interrumpir la paralización por más de tres meses bajo sanción de caducidad.

${ }^{124}$ No parece haber entonces una acumulación propiamente tal. 


\section{4.- NULIDAD DE DERECHO PUBLICO DE LAS PERTENENCIAS MINERAS POR IRREGULAR TRAMITACION E INCOMPETENCIA DEL. ORGANO QUE LAS CREA}

Más complejo es, con todo, la resolución de aquellos casos en que -como se dijoencontrándose presentada la demanda de oposición a la solicitud de mensura, decretada la acumulación de autos pero no cumplida, el demandante continúa el procedimiento constitutivo ante otro Tribunal y obtiene precisamente sentencia concesional, escamoteando por esa vía el juicio y burlando el contradictorio.

Es, evidentemente, una actuación de mala fe, en la medida en que si el propio demandante formalizó su demanda mediante la presentación de la misma ante el Tribunal competente solicitando la acumulación de autos, conociendo la providencia a su demanda y el decreto de acumulación, pero después por algún tipo de artilugio evita que el oficio respectivo implique la efectiva remisión del expediente para su acumulación, sorprendiendo al Juez del Tribunal originalmente competente, obtenga una sentencia concesional que ulteriormente se inscriba en el Conservador de Minas, quebrando todo el sistema legal minero y con ello los basamentos constitucionales de que hemos hablado.

Así las cosas, se plantea el conflicto con un concesionario con un derecho prima facie preferente por su antelación, con sentencia constitutiva inscrita, pero burlando el litigio que el mismo provocó con su demanda, en la que solicitó acumulación de autos.

En ese escenario, bien podría pensarse que la discusión es baladí ya que en definitiva ciertamente quien obtuvo la sentencia constitutiva en esas condiciones es en todo caso el titular de un derecho preferente.

Sin embargo, fuera de que los fines no justifican los medios -y el hecho de que efectivamente se trate de un titular preferente no lo libera de sus cargas procesales ni le autoriza a eludir los procedimientos que rigen para todos- hay en su conducta la infracción de las siguientes garantías constitucionales:

a) La garantía del debido proceso legal racional y justo, en la medida en que se procura el reconocimiento de su derecho casi por una vía autotutelar.

b) La igualdad ante la ley, ya que si todos deben acudir a un determinado procedimiento para obtener el reconocimiento de sus derechos, no se ve por qué este privilegiado manifestante no deba hacerlo.

c) Pero, por sobre todo, se infringe el principio de legalidad y de supremacía constitucional.

En efecto, según señalamos supra, el otorgamiento y régimen de las concesiones mineras está altamente constitucionalizado, particularmente a través de sus supuestos orgánicos y procedimentales.

Al estar dominicalizados los yacimientos mineros existentes en Chile, cuyo dominio absoluto, exclusivo, inalienable e imprescriptible lo tiene el Estado, sólo él puede otorgar parcelas exclusivas en el aprovechamiento de tales recursos naturales. 
El Estado ha resuelto en su estatuto constitucional, que dicho aprovechamiento se verifique mediante concesiones mineras judiciales creadoras de derechos reales de aprovechamiento minero, sobre los cuales su titular tenga propiedad privada.

En consecuencia, no puede apartarse en lo concreto dicho esquema un ápice de la legalidad, particularmente porque existe una doble vinculación a dicho principio: en primer lugar, por el principio de legalidad de los órganos del Estado, que actúan siempre y únicamente en forma válida, previa investidura regular de sus integrantes, dentro de su competencia y en la forma que prescriba la ley; $y$, en segundo lugar, porque sólo por ley y conforme a ella puede adquirirse, conservarse y perderse el dominio de toda clase de bienes, incluso el bien incorporal pertenencia minera.

Así que desentrañar el exacto sentido y alcance de la ley en esta materia, no es más que cumplir los mandamientos y valoraciones constitucionales.

En esencia, puede decirse lo siguiente:

a) La competencia de un Tribunal es la facultad que éste tiene de conocer, juzgar y ejecutar todo lo relativo a los asuntos que la ley ha colocado dentro de la esfera de sus atribuciones.

b) En materia minera, la competencia natural de un Tribunal está definida espacialmente por la ubicación del punto medio o del punto de interés de la concesión minera de exploración o explotación solicitada, según el caso, competencia que se fija al momento de iniciar el trámite y en general no se altera por causa ulterior, conforme a la regla clásica de la radicación o fijeza establecida en el artículo 109 del Código Orgánico de Tribunales, principio que se proyecta también a todo el resto de las reglas de la competencia, particularmente la regla de la extensión y el principio de inexcusabilidad de los Tribunales en esta materia.

c) Cuando en base a un procedimiento constitutivo minero en trámite, se desea hacer oposición a una solicitud de mensura con apoyo en una manifestación minera en trámite en los casos en que procede la acumulación, la presentación de la demanda en el otro expediente constituye un hecho propio contra el cual el demandante no puede protestar válidamente, ${ }^{125}$ que significa la transformación por su misma acción del asunto en una materia contenciosa, ante otro Tribunal, y además por el decreto que accede a la solicitud de acumulación de autos la competencia del Tribunal original termina quedando incluso suspendido el procedimiento constitutivo, el cual sólo podrá continuar en el caso y en la medida que la sentencia que se pronuncie conforme al artículo 69 del Código de Minería le reconozca algún área de preferencia. $Y$, en ese caso, con todo el trámite constitutivo seguirá ante el nuevo Tribunal, en los términos del artículo 70 , inciso segundo, del Código Minero.

d) No es válida a este respecto la invocación del debido proceso y de la garantía constitucional de la propiedad de la concesión minera constituida en tales írritas condiciones. Dicha misma concesión minera es nula de Derecho Público, de manera originaria e insanable, que incluso puede ser declarada de oficio, por lo que, si ya de hecho tal concesión no existe, mal podrá estar protegida por las garantías del debido proceso y de la propiedad privada. Además, no vale la protesta contra el hecho propio.

${ }^{125}$ En otros ámbitos juridicos, se ha llamado a este principio "doctrina de las astraintes" 
Tales fundamentos han sido reconocidos por la doctrina y en explícitos fallos judiciales.

En efecto, la llustrísima Corte de Apelaciones de Antofagasta con fecha 2 de Agosto de 1993, declaró que: "... son hechos de la causa, la existencia de un juicio contencioso sobre constitución de propiedad minera en le Cuarto Juzgado de Letras Civil de Mayor Cuantía, Rol № 13.269 caratulado "Callejas Callejas Maximiliano con Sociedad Química y Minera de Chile S.A.", demanda de oposición a la mensura en contra de la Sociedad Química y Minera de Chile S.A., que había solicitado la mensura de sus pertenencias "Filo 1-II", pidiendo el actor Maximiliano Callejas Callejas que declarara el derecho preferente para mensurar sus pertenencias denominadas "Icalma 1 a Icalma 40". en la forma indicada en la solicitud, sin perjuicio del derecho del demandado de ejecutar su mensura de las pertenencias "Filo 1-II" sobre los terrenos francos resultantes, todo ello de conformidad al artículo 61 № 2 del Código de Minería, pidiendo en el tercer otrosí de la demanda que rola a fs. 64 , que de conformidad a lo dispuesto en el artículo 63 del Código de Minería se acumule al expediente de Soquimich del Cuarto Juzgado de Letras, el expediente relativo a las pertenencias Icalma 1 a Icalma 40 , rol 6.860 del Primer Juzgado de Letras, dictándose con fecha 31 de marzo de 1992 la resolución que citaba a comparendo y ordena la acumulación pedida, resolución que se notificó por el estado diario, según rola a fs. 69 .

... habiéndose transformado en contencioso el asunto, es Juez competente para conocer de esta materia el que tramita el expediente de manifestación del demandado conforme lo señala perentoriamente el artículo 63 del Código de Minería. "En el mismo escrito de oposición, pedirá que se ordene la acumulación de su expediente de manifestación al del demandado" y en este caso es el Juez del Cuarto Juzgado de Letras de Antofagasta, el que conforme al artículo 69 del Código de Minería, deberá dictar la sentencia respectiva, prosiguiendo la constitución de la propiedad minera en conformidad al artículo 70 inciso $2^{\circ}$ del mismo cuerpo legal citado.

... los efectos de la demanda de oposición rigen sin que sea necesaria la notificación al demandado, como claramente lo señala el artículo 70 en su inciso primero del Código de Minería, por lo que el Juez del Primer Juzgado de Letras de Antofagasta era absolutamente incompetente para seguir conociendo de la constitución de la propiedad minera "Icalma 1 a Icalma 40", Rol 6.860, de propiedad de Maximiliano Callejas Callejas, por haberse transformado esa materia de voluntaria a contenciosa, siendo competente desde ese momento, como se ha expresado, el Juez del Cuarto Juzgado de Letras, en la causa Rol 13.269; habiéndose presentado la demanda de oposición con fecha 19 de febrero de 1992, dictándose su providencia el 31 de marzo de ese mismo año, la que fue notificada por el estado diario, siguiéndose los trámites del procedimiento sumario;

... si bien la acumulación material de los expedientes se produjo después del 4 de mayo de 1992, la acumulación jurídica producida en el presente caso con la oposición planteada por el actor en el proceso conocido por el Cuarto Juzgado como ha quedado ya expresado, surtió sus efectos desde el 31 de marzo de 1992;

... la sentencia dictada por el Juez del Primer Juzgado de Letras en el proceso Rol 6.860 sobre constitución de propiedad minera "Icalma 1 a Icalma 40", con posterioridad al 31 de marzo de 1992, la hizo sin tener competencia para ello, y es nula, toda vez que es absolutamente incompetente para conocer de dicha materia, en razón que el asunto se había transformado en contencioso, regido por las reglas del juicio sumario y de 
conocimiento de otro tribunal, antecedentes estos que son del conocimiento del quejoso, el que siguió tramitando como voluntaria una causa que era contenciosa, conociendo además cual era el Tribunal competente, pues el tiene la calidad de demandante en el proceso Rol 13.269 del Cuarto Juzgado Civil de Antofagasta.

... atendido el vicio que presentaba la sentencia dictada por el Juez del Primer Juzgado de Letras de Antofagasta, el 4 de mayo de 1992, la nulidad podía solicitarse en el tiempo y la forma que hizo y al acogerla el Juez ha actuado legalmente" (redacción Ministro señor Manuel Zañartu Vera). Dicha sentencia fue confirmada por la Excelentísima Corte Suprema .

Asimismo, dicha misma Corte de Apelaciones en sentencia de fecha 11 de Agosto de 1992, aplicó idéntica doctrina, al resolver que: "... en síntesis, el Juzgado de Letras de Tocopilla estaba conociendo de un procedimiento constitutivo voluntario de concesiones mineras de explotación, pero no tiene competencia para conocer de un juicio de oposición a la solicitud de mensura encargado por ley al Juzgado de Letras de Pedro de Valdivia;

...la disposición del art. 86 del Código de Minería que señala que dictada la sentencia constitutiva de la concesión, quedan saneados todos los vicios procesales y las caducidades en que se pueda haber incurrido en la tramitación, no es aplicable en la especie, porque supone un asunto voluntario, no cuando se ha transformado en contencioso el negocio, por aplicación del artículo 63 del Código de Minería, ya que en tal caso las prescripciones del fallo están contempladas en el art. 69;

... se ha infringido una norma de orden público establecida en la Constitución, en su artículo $7^{\circ}$ en cuanto prescribe que ninguna magistratura, ninguna persona ni grupo de personas pueden atribuirse, ni aún a pretexto de circunstancias extraordinarias, otra autoridad o derechos que los que expresamente se les haya conferido en virtud de la Constitución o las leyes, ya que el juzgado de Tocopilla no podía seguir tramitando el expediente voluntario sobre constitución de la concesión de explotación;

... el tribunal puede de oficio declarar una nulidad cuando ella resulta de haberse transgredido un precepto de orden público, dado que las formalidades procesales están establecidas, las más, de la veces, en garantía del derecho de defensa de los litigantes, es un interés de orden privado. Si transcurren las oportunidades legales sin que las partes hayan hecho valer su derecho a la nulidad, se presume que tácitamente han renunciado a él, pero la situación es diversa cuando se ha faltado a trámites impuestos por razones de orden público porque en estos casos, los vicios no se sanean. El tribunal debe velar de oficio y sin requerimiento de las partes, por el estricto cumplimiento de este orden de leyes: de oficio debe anular toda actuación que no se ajuste a ellas.

Es cierto que terminado el proceso, ejecutoriada la sentencia final, ya existía un interés superior en mantener la autoridad de cosa juzgada y desde ese entonces parte alguna del proceso podrá anularse o modificarse, sea que se observen vicios que afecten al sólo interés privado de las partes, sea que se trate de irregularidades de orden público. Sin embargo, en el caso de autos el proceso no ha terminado, sino que se transformó en contencioso a través de la acumulación exigida en el artículo 63 del Código de Minería y la sentencia debe atender a la norma del artículo 69 y no a la del art. 86 del mismo cuerpo legal citado;

... entenderlo de otra forma, haría inconjugables las normas del Código de Minería. En efecto, el artículo 34 del mismo señala que el procedimiento no contencioso de 
constitución de la concesión minera no le será aplicable lo dispuesto en los artículos 92 y 823 del Código de Procedimiento Civil. El artículo 823 del Código de Procedimiento Civil dice que si a la solicitud presentada se hace oposición por legítimo contradictor, se hará contencioso el negocio y se ajustará a los trámites del juicio que corresponda. Por su parte el artículo 92 del mismo cuerpo de leyes se refiere a la acumulación. De la manera como la juez a quo ha interpretado el artículo 86 del Código de Minería, tanto esta disposición legal como la norma del artículo 34 en su parte citada, dejarían marginado de significado y utilización todo lo relativo a las oposiciones a la solicitud de mensura, desde los artículos 61 a 70 del Código de Minería, a pesar que el inc. final del art. 34 dice que lo dispuesto es sin perjuicio de lo establecido en los arts. 61 y 70 y en el art. 84;

... en el caso de autos, el juicio de oposición a la mensura hacía imperiosa la incompetencia del Juzgado de Letras de Tocopilla y el envío del expediente sobre gestión voluntaria de constitución de concesión de explotación, para su acumulación al Juzgado de Pedro de Valdivia, hallándose impedido aquél para seguir conociendo un asunto que por su materia, había dejado de ser voluntario para transformarse en contencioso;

... dicha incompetencia absoluta del Juzgado de Letras de Tocopilla debe ser motivo de la invalidación de oficio de todo lo obrado a partir del 22 de Junio de 1991. fecha en que se proveyó el escrito de oposición de la parte del señor Andía, ordenándose la consiguiente acumulación ante el Juzgado de Pedro de Valdivia, en virtud de las disposiciones de los artículos $7^{2}$ de la Constitución que contempla expresamente tal nulidad, art. $7^{\circ}$ del Código Orgánico de Tribunales, que dispone que los tribunales sólo podrán ejercer su potestad en los negocios y dentro del territorio que la ley les hubiere respectivamente asignado; art. 8 , ningún tribunal puede avocarse al conocimiento de causas o negocios pendientes ante otro tribunal, a menos que la ley le confiera expresamente esta facultad, art. 10 del mismo cuerpo de leyes, reclamada su intervención en forma legal y en negocios de su competencia, no podrán excusarse de ejercer su autoridad ni aún por falta de ley que resuelva la contienda sometida a su decisión. Ello tiene como contrapartida que si se reclama la intervención de un tribunal en negocios que no son de su competencia, com ocurrió en autos con el Juzgado de Letras de Tocopilla cuando el negocio se transformó en contencioso, debe abstenerse de ejercer su autoridad. Esta norma está repetida en el artículo 73 de la Constitución. También el artículo 209 del Código de Procedimiento Civil contiene un precepto explícito en orden a que una de las declaraciones que por ley es obligatoria para los jueces es aquella en que se establece su propia incompetencia.

En conclusión, corresponde declarar de oficio la nulidad de lo actuado ante el Juzgado de Letras de Tocopilla en la forma pedida por el incidentista.". Redacción Ministro Titular Julio Campo Herreros.

La importancia de esta jurisprudencia fue plenamente captada por el profesor Pablo Rodríguez Grez quien, en su obra Inexistencia y Nulidad en el Código Civil Chileno, señala que: "Esta sentencia se refiere a la constitución de la propiedad minera, de modo que las normas a que alude no son meramente procesales, sino también sustantivas. Se reconoce en ella que los vicios que tienen origen en la transgresión de normas de "Orden Público" no se sanean y que el tribunal debe declarar de oficio la nulidad, atendiendo al estricto cumplimiento de este tipo de leyes. Para explicar, en el caso concreto del proceso judicial a que da lugar la constitución de la propiedad minera, que estos vicios no puedan atacarse luego de dictada la sentencia constitutiva, ejecutoriada que se encuentre, 
sostiene que, en el evento, se sobrepone un "interés superior" que justifica el incumplimiento de las normas de orden público. Creemos que esta decisión es correcta, ya que el efecto más característico de las normas de orden público es que ellas quedan bajo el amparo del tribunal, el cual ante su infracción debe obrar de oficio para corregir su infracción.".

En el ámbito del Derecho Minero propiamente tal la plena validez de tal predicamento jurisprudencial se sustenta en el informe del proyecto de Código de Minería del Presidente de la Primera Comisión Legislativa a la $\mathrm{H}$. Junta de Gobierno, cuando comenta, a propósito del artículo 95 del proyecto, que tipifica las causales de nulidad que: "el ejecutivo formuló indicación para sustituir los números $1^{\circ}, 2^{\circ}, 3^{\circ}$ y $4^{\circ}$ por otros: $1^{\circ}$ con el fin de eliminar como causal de nulidad de la concesión la circunstancia de que ésta se haya constituido por autoridad incompetente o carente de jurisdicción, en razón de que dicha situación está contemplada en el artículo $7^{\circ}$ de la Constitución Política; y $2^{\circ}$, con el fin de adecuar en un mejor ordenamiento las causales de nulidad que contempla este artículo".

Ya también en el ámbito del Derecho Público el profesor Soto Kloss ha formulado muy latamente la doctrina de la nulidad de Derecho Público en la que calza perfectamente la situación procesal minera por nosotros comentada. ${ }^{126}$

Todo esfuerzo por hacer consistentes las doctrinas y eficaz la aplicación de las normas en materias jurídicas, contribuye concretamente a modelar un orden social y económico más acorde con los valores constitucionales y en último término con un pleno desarrollo del país.

${ }^{126}$ Soto Kloss, Eduardo, Op. cit. loc. cit. 